\section{Central Mental Hospital study}

Dear Editor - L Siponmaa, M Kristiansson, D .Jonson, A Nyden, C Gillberg (2001). Juvenile and Youth Adult Mentally Disordered Offenders, The Role of Child Neurospychiatric Disorders, Journal of the American Academy of Psychiatry Law, 29, 420-6. They point out that "Attention Deficit Disorder or Attention Deficit Hyperactivity Disorder has been reported in $55 \%$ of juvenile delinquents". This refers to a study by Zagar R., Arbit J., Hughes J.R., Busell R.E., Busch K. (1989). Developmental and Disruptive Behaviour Disorders among Delinquents. Journal of the American Academy of Child and Adolescent Psychiatry, 28: 437 - 40. Scragg and Shah describe the rate of Asperger's syndrome in patients in adult Forensic Security Hospitals as being between $1.5 \%-2.3 \%$. This is higher than in the general population at $0.4 \%$. Scragg P., Shah A. Prevalence of Asperger's syndrome in a Secure Hospital. British Journal of Psychiatry, 165: 679 - 82, 1994. Ehlers S., Gillberg C. (1993). The Epidemiology of Asperger's syndrome: A total population study. Journal of Child Psychology Psychiatry, 34; $1327-50$.

Siponmaa et al found that "the diagnosis of Pervasive Developmental Disorder Not Otherwise Specified and Asperger's syndrome were statistically more frequent in the arson group than it was in other crime groupings" (Page 423), They found that the rate of Pervasive Developmental Disorder (15\% definite cases) was particularly striking and we are confident that this represents at least a 15-fold increase over the incidence in the general population (Page 423). Pervasive Development Disorder is an overarching category which includes Autism Spectrum Disorder and Asperger's syndrome. Siponmaa et al. found "the rate of definite cases of Asperger's syndrome (3\%) was higher than that in the general population (0.4\%) but was of the same order of magnitude as that found by Scragg and Shah (1.5\% -
2.3\%), who studied adult subjects in a Secure Hospital who were undergoing forensic psychiatric treatment" (Page 424). They point out that "what's needed now is a systematic prospective study of autistic-type problems and attention disorders in cohorts of forensic psychiatric patients, using the most appropriate and up-to-date methodology and relevant control groups".

Michael Fitzgerald

Henry Marsh Professor Child \& Adolescent Psychiatry Trinity College Dublin Ireland.

\section{The Dissociative Experiences Scale \\ Re: The Dissociative Experiences Scale: Replacement items for use with the visually impaired}

Dear Editor - Over the last twenty years a number of selfreport instruments designed to measure the frequency and types of dissociative experiences have been developed. Presently, the most frequently used is the Dissociative Experiences Scale (DES1), a 28-item self-report instrument that measures the frequency with which individuals experience a wide variety of dissociative phenomena (eg. absorption, imaginative involvement, depersonalisation, derealisation, amnesia). As dissociation is associated with altered sensory perceptions, it is argued that established measures of dissociation, including the DES, are unsuitable for use with the visually impaired given the wording of a number of items (see Table 1).

Consequently, there was a clear imperative to revise the most commonly used measure of dissociation, the DES, for use among the visually impaired, by replacing items identified as being unsuitable for this population with suitably equivalent ones. Three clinicians independently identified six items

Table 1: Six items of the DES (original and revised versions items).

Original item

1. Some people have the experience of driving or riding in a car or bus or subway and suddenly realising that they don't remember what has happened during all or part of the trip.

7. Some people sometimes have the experience of feeling as though they are standing next to themselves or watching themselves do something and they actually see themselves as if they were looking at another person.

11. Some people have the experience of looking in the mirror and not recognizing themselves.

17. Some people find that when they are watching television or a movie they become so absorbed in the story that they are unaware of other events New Equivalent item

26. Some people sometimes find writings, drawings, or notes among their belongings that they must have done but cannot remember doing.

28. Some people sometimes feel as if they are looking at the world through a fog so that people and objects appear far away or unclear.

\section{New equivalent item}

1. Some people have the experience while being driven in a car or riding on a bus or train of suddenly realising that they don't remember what has happened during all or part of the trip.

7. Some people sometimes have the experience of feeling as though they are standing next to themselves and believing they are in the presence of another person.

11. Some people have the experience of touching a part of their own body and feeling as if it doesn't belong to them.

17. Some people find that they become so absorbed in listening to the radio or reading a book that they are unaware of other events happening around them.

26. Some people sometimes find things among their belongings which they must have made or written but cannot remember doing.

28. Some people sometimes feel as if the place they are in seems unreal or strange to them. 